\title{
Association between pyuria and uropathogen in suspected urinary tract infection
}

\author{
M.J. Haja Abdul Nazeer ${ }^{1}$, Y. Kavitha ${ }^{2}$ \\ ${ }^{1}$ Dr. Haja Abdul Nazeer M.J, Professor, ${ }^{2}$ Dr. Kavitha. Y, Assistant Professor, Department of Microbiology, Vinayaka \\ Missions Medical College, Karaikal, Pondicherry (U.T), India.
}

Address for Correspondence: Dr Yedla Kavita, Assistant Professor, Department of Microbiology, Vinayaka Missions Medical College, Karaikal. E-mail: drkavitapes@gmail.com

\begin{abstract}
Background: Urinary tract infections (UTI) are one of the most common infectious diseases diagnosed in outpatients as well as in hospitalized patients, and can lead to significant mortality. Several rapid methods have been developed in diagnosing urinary tract infections such as microscopic examination, chemical tests, and automated systems. Thus, in this study we aimed at determining pyuria in suspected UTI patients and their association with uropathogen. Materials and Methods: A total of 379 clean catch mid-stream urine samples were collected in sterile containers. Manual microscopy is used to determine pyuria. All the urine samples inoculated on routine bacteriological media. Results: Out of 379 urine samples, 181 yielded significant bacterial growth. Patients belonged to age group 21-30 were more commonly had significant growth followed by 11-20 years age group. Escherichia coli was the most common organism isolated. Majority of urine specimens which showed plenty of pus cells per high power field yielded significant growth. Escherichia coli was most commonly associated with pyuria. Conclusion: As the number of pus cells in urine increases, the chance of yielding significant bacterial growth is also high. Overall, significant pyuria was observed among specimens yielded Gram negative bacilli than Gram positive cocci. Among Gram negative bacilli, Escherichia coli was most commonly accompanied with pyuria.
\end{abstract}

Key words: Pyuria, uropathogen, Escherichia coli

\section{Introduction}

Urinary Tract Infections (UTIs) are one of the most common infectious diseases and nearly $10 \%$ of people will experience a UTI during their life time [1]. It remains a major public health problem in terms of morbidity and financial cost with an estimated 150 million cases per annum worldwide, costing global economy in excess of 6 billion dollars [2].

Although UTIs occur in both men and women, clinical studies suggest that the overall prevalence of UTI is higher in women. Uncomplicated UTIs in healthy women have an incidence of 50/1000/year. Approximately $20 \%$ of all UTIs occur in men [3]. UTI is mostly caused by gram negative aerobic bacilli found in GI tract. Organism included in this family are the E. coli, Klebsilla, Pseudomonas aeruginosa,

Manuscript received: $17^{\text {th }}$ May 2017

Reviewed: $28^{\text {th }}$ May 2017

Author Corrected: $7^{\text {th }}$ June 2017

Accepted for Publication: $14^{\text {th }}$ June 2017
Enterobacter, Proteus and serratia species. Other common pathogens include Staphylococcus epidermidis, Staphylococcus saprophyticus and Enterococcus species which presumably result in UTI following colonization of the vagina or perianal skin. Less common organism such as Gardenella vaginalis, Mycoplasma species and Ureaplasma urealyticum may infect patients with intermittent or indwelling catheters [4].

UTIs are challenging, not only because of the large number of infections that occur each year, but also because the diagnosis of UTI is not always straightforward. Physicians must distinguish UTI from other diseases that have a similar clinical presentation, some UTIs are asymptomatic or present with atypical signs and symptoms [5]. Laboratory examination of urine specimens accounts for a large part of the workload in many laboratories. In fact, in many clinical 
laboratories, urine cultures are the most common type of culture, accounting for $24 \%-40 \%$ of submitted cultures; as many as $80 \%$ of these urine cultures are submitted from the outpatient setting [5].

Even though, urine culture is gold standard method in diagnosing UTI, it is time consuming, expensive and requires culture set up. Hence, clinicians rely on urine analysis which is simple and inexpensive.

Pyuria is the most useful analyte for diagnosis of infection and the clinician has a choice between multiple laboratory tests. The gold standard for the definition of pyuria is the leukocyte excretion rate.

A leukocyte excretion rate of $>400000$ cells $/ \mathrm{h}$ correlates well with symptoms of dysuria and frequency as well as the presence of bacteriuria.[6]

Hence, we aimed at determining the incidence of pyuria and its association with uropathogen.

\section{Materials and Methods}

This is a prospective observational study in which a total of 379 urine samples were collected from both inpatient and outpatient departments of Vinayaka Mission's Medical College and Hospital. 119 were from males and 260 were from females. All the received samples were processed in the department of microbiology. Clean catch mid-stream urine samples were collected in sterile containers.

Manual microscopy is used to determine pyuria. Centrifuging 10-20 ml urine for approximately $5 \mathrm{~min}$, then resuspending the sediment in a drop up to $0.2 \mathrm{ml}$ supernatant $[7,8]$.

Then the preparation was examined under high power objective. Significant pyuria was defined by presence of $\geq 5 \mathrm{WBCS} / \mathrm{hpf}[9]$.

Urine samples were inoculated on blood agar and Mac Conkey agar plates by direct streaking with sterile calibrated platinum wire loops. Both plates were incubated overnight at $37^{\circ} \mathrm{C}$.

Diagnosis of bacteriuria was made by bacterial count. A bacterial colony count of $10^{5} / \mathrm{ml}$ of urine was considered as an evidence of significant bacteriuria and established the diagnosis of UTI [10].

Exclusion criteria: Specimens yielded growth more than two organisms were considered as contaminants and excluded from the study.

Statistical method: Simple percentage method was used to analyse the data.

\section{Results}

A total of 379 urine samples were processed during the study period. 119 were from males and 260 were from females. 181 urine samples yielded significant bacterial growth. Patients belonged to age group 21-30(75.24\%) were more commonly had significant growth followed by 11-20(48.15\%) years age group [Table 1].

Table-1: Age wise distribution of positive and negative bacterial growth

\begin{tabular}{|c|c|c|c|c|}
\hline S. No & Age & Culture positive & Culture negative & Total \\
\hline 1 & $1-10$ & $32(41.56 \%)$ & $45(58.44 \%)$ & 77 \\
\hline 2 & $11-20$ & $26(48.15 \%)$ & $28(51.85 \%)$ & 54 \\
\hline 3 & $21-30$ & $79(75.24 \%)$ & $26(24.76 \%)$ & 86 \\
\hline 4 & $31-40$ & $22(25.58 \%)$ & $64(74.42 \%)$ & 20 \\
\hline 5 & $41-50$ & $9(45 \%)$ & $11(55 \%)$ & 22 \\
\hline 6 & $51-60$ & $7(31.82 \%)$ & $15(68.18 \%)$ & 15 \\
\hline 7 & $>60$ & $6(40 \%)$ & $9(60 \%)$ & 205 \\
\hline
\end{tabular}

Escherichia coli $66(36.46 \%)$ was the most common organism isolated, followed by Klebsiella species $41(22.65 \%)$, Staphylococcus aureus 28(15.47\%) and Pseudomonas aeruginosa 13 (7.18\%) [Table 2]. 
Table-2: Bacteria isolated from urine specimens

\begin{tabular}{|c|c|c|}
\hline S. No & Bacteria isolated & Number (\%) \\
\hline 1 & E.coli & $66(36.46 \%)$ \\
\hline 2 & Klebsiella species & $41(22.65 \%)$ \\
\hline 3 & Staphylococcus aureus & $28(15.47 \%)$ \\
\hline 4 & Pseudomonas aeruginosa & $13(7.18 \%)$ \\
\hline 5 & Enterococci & $7(3.87 \%)$ \\
\hline 6 & Proteus species & $7(3.87 \%)$ \\
\hline 7 & Enterobacter & $5(2.76 \%)$ \\
\hline 8 & CONS & $3(1.66 \%)$ \\
\hline 9 & NFGNB & \\
\hline
\end{tabular}

CONS: Coagulase negative staphylococci, NFGNB: Non fermenting gram negative bacilli

One hundred and seventeen urine samples showed pus cells in the range of 1-5/HPF. Out of 117 , only $21(17.95 \%)$ showed significant bacterial growth. 41 urine specimens showed plenty of pus cells out of which $36(87.80 \%)$ had significant growth [Table 3]

Table-3: Distribution of pyuria among culture positive specimens

\begin{tabular}{|c|c|c|c|}
\hline S. No & No. of Pus cells/HPF & No. of Specimens & Culture Positive \\
\hline 1 & $1-5$ & 117 & $21(17.95 \%)$ \\
\hline 2 & $6-10$ & 99 & $48(48.48 \%)$ \\
\hline 3 & $11-15$ & 63 & $38(60.32 \%)$ \\
\hline 4 & $16-20$ & 59 & $38(64.41 \%)$ \\
\hline 5 & Plenty & 41 & $36(87.80 \%)$ \\
\hline
\end{tabular}

Table-4: Association between isolated bacteria and pus cells

\begin{tabular}{|c|c|c|}
\hline Bacteria isolated & $\leq \mathbf{1 0 p u s}$ cells/HPF & $>\mathbf{1 0 p u s ~ c e l l s / H P F ~}$ \\
\hline E.coli & $26(27.08 \%)$ & $40(47.06 \%)$ \\
\hline Klebsiella species & $27(28.12 \%)$ & $14(16.47 \%)$ \\
\hline Staphylococcus aureus & $15(15.62 \%)$ & $13(15.29 \%)$ \\
\hline Pseudomonas aeruginosa & $8(8.33 \%)$ & $3(5.88 \%)$ \\
\hline Enterococci & $8(8.33 \%)$ & $1(1.18 \%)$ \\
\hline Proteus species & $6(6.25 \%)$ & $4(4.70 \%)$ \\
\hline Enterobacter & $3(3.12 \%)$ & $2(2.35 \%)$ \\
\hline CONS & $3(3.12 \%)$ & $3(3.53 \%)$ \\
\hline NFGNB & $0(0 \%)$ & $85(46.96 \%)$ \\
\hline Total & $96(53.04 \%)$ & \\
\hline
\end{tabular}

\section{Discussion}

Manual microscopy is widely employed to determine pyuria. But the results are highly variable depending on the laboratory, technician and urine sample [7]. In the present study, majority of urine samples $(n=117)$ collected and examined under high power objective showed pus cells in the range of 1-5. Only 21(17.95\%) urine samples yielded significant bacterial growth. These results are similar with the study conducted by
Anushree et al, in which 240 out of 260 urine samples showed pus cells in the range of $1-5 / \mathrm{HPF}$ and only $4(1.6 \%)$ urine samples showed significant bacterial growth [11]. In this study, 262 samples showed significant pyuria ( $>5$ pus cells/HPF). Out of 262 urine samples which had pus cells >5/HPF, 160(61.07\%) samples showed significant bacterial growth. The study conducted by Kattel et al observed $53.9 \%$ urine samples 
Research Article

with significant bacterial growth and significant pyuria [12]. Other study which was conducted by Anjila Dongol et al, also found $84.09 \%$ (74/88) samples had significant pyuria with culture positive [13]. Significant bacterial growth was seen in 21(17.95\%) urine samples which showed pus cells in the range of $1-5 / \mathrm{HPF}$. Previous studies conducted by Ginsburg and Maskell found bacteriuria without pyuria with the rate of $15 \%$ and $44 \%$ respectively $[14,15]$.

In a study conducted by Samia Khamees, 23\% urine specimens showed bacteriuria without pyuria (or the presence of puss cells less than 5) [16]. Bacteriuria without significant pyuria often occur in cases of asymptomatic patients, patients with diabetes, enteric fever or bacterial endocarditis whereas significant pyuria with sterile bacterial culture occur in patients with prior antibiotic use, renal tuberculosis, corticosteroid administration, analgesic nephropathy, renal calculi or in the presence of bacteria that are not able to grow in the routine culture media [12].

In the present study, the significant bacterial growth was found to be high $(87.80 \%)$ in samples with plenty of pus cells per HPF which differs with the previous studies. Anjila Dongol et al and Dhakal et al observed that the presence of 5-10 pus cells per HPF could be a good marker of UTI $[13,17]$. The chance of getting significant bacterial growth was high when pus cells are more per HPF. This correlates well with the study conducted by Anushree et al [11].

The diagnostic accuracy and microscopic result analysis are influenced by specimen processing (centrifuged/ uncentrifuged and stained/unstained) the method of quantifying leucocytes (per microscopic high power field/ per cubic millimeter) and cutoff value to define pyuria [18]. Previous studies reported that examining uncentrifuged urine is easier and less time-consuming, hence it is suitable for the out-patient department and however, it is reassuring that no significant difference was found between the results of centrifuged and uncentrifuged specimens [19].

However, pyuria alone cannot be used for detecting bacterial pathogen in patients with significant bacteruria. In our study, pyuria was most commonly observed among females. In females, inflammation of the external surfaces of the urinary organs or contiguous infection, potentially resulting in pyuria and sometimes a UTI. This is similar to the study conducted by Hooker et al [20]. As per Hooker et al women had higher incidence of pyuria but the proportion with positive cultures was not different between women and men with pyuria. Macdermott stated that there was no association between degree of pyuria and a significant urine culture [21]. Further, Bachman et al concluded that pyuria on urine microscopy was poor in identifying asymptomatic bacteruria [22]. Wammanda et al found positive urine culture with significant bacteria in $24.3 \%$, urine microscopy for significant leucocyturia had a sensitivity of $51.1 \%$ [23]. But, Shaw et al reported that urine WBC count was sensitive in detecting UTI [24].

In the present study Escherichia coli(36\%) was the predominant pathogen. This is in accordance with previous studies [25]. Other study conducted by Kristiansen found $81.5 \%$ of UTI caused by E.coli. Second most common uropathogen was Klebsiella spp (22\%) followed by Staphylococcus aureus(15\%).[26] But in other studies, lower proportion of UTI was caused by Klebsiella spp (8.4\%) [27,28].

In our study, When infections were analyzed by the organisms causing infection, Gram negative Bacilli were mostly accompanied with pyuria than gram positive cocci. However, among Gram negative bacilli, Klebsiella and Pseudomonas aeruginosa were less likely to elicit pyuria. This is in accordance with the study conducted by shaik et al [29].

Others studies also reported the frequent absence of pyuria in noncatheterized and catheterized patients with urinary tract infection caused by coagulase-negative staphylococci or yeast [30,31].

The reasons underlying these observations are not entirely clear. While CAUTI caused by staphylococci, enterococci, or yeasts occasionally leads to bloodstream infection, especially if urinary tract obstruction occurs [31]. The degree of urinary tract inflammation elicited by these organisms is clearly not as great as occurs with the gram-negative bacilli. Coagulase - negative staphylococci have been shown in animal models of infection to incite far less cytokine release than gram negative bacilli [32]. Few studies reported correlation between method of sample collection and significant bacterial growth [31]. Virtanen et al, found only $6 \%$ false positive in clean-voided specimens [33] and Houston found that $86 \%$ (75 out of 87 ) of 'non-infected' children gave negative results (less than 10,000 organisms/ml.) in mid-stream urine culture [34]. In 
Research Article

repeat cultures, using the same method of cleansing and collection, definite negative results were obtained in all those with significant growth. But in our study no repeat urine culture was performed due to lack of patient follow up especially samples received from outpatient departments. Even other study showed, approximately $50 \%$ patients no longer had pyuria on a repeat urinalysis [20]. In our study, majority of samples especially received from outpatient departments were not subjected to repeat urinalysis which remained as limitation of the study. No proper information was obtained from out patients regarding antimicrobial therapy received before submitting urine sample and remained as another limitation of the study.

\section{Conclusion}

Majority of urine samples received from suspected UTI patients showed no growth in spite of significant pyuria on routine bacteriological media. As the number of pus cells in urine increases, the chance of yielding significant bacterial growth is also high. Overall, significant pyuria was observed among specimens yielded Gram negative bacilli than Gram positive cocci. Among Gram negative bacilli, Escherichia coli was most commonly accompanied with pyuria.

Funding: Nil, Conflict of interest: None initiated, Permission from IRB: Yes

\section{References}

1. Delanghe JR, Kouri TT, Huber AR, HannemannPohl K, Guder WG, Lun A, Sinha P, Stamminger G, Beier L. The role of automated urine particle flow cytometry in clinical practice. Clin Chim Acta. 2000 Nov;301(1-2):1-18.

2. Dash M, Padhi S, Mohanty I, Panda P, Parida B. Antimicrobial resistance in pathogens causing urinary tract infections in a rural community of Odisha, India. J Fam Community Med 2013;20(1):20-6.

3. Sood S, Gupta R. Antibiotic resistance pattern of community acquired uropathogens at a tertiary care hospital in Jaipur, Rajasthan. Indian J Community Med 2012;37(1):39-4.

4. Chedi, B.A.Z. Wannang, N.N, Halliru, M.A. Bichi, L.A., A seven months retrospective study of urinary tract infection among patients at Aminu kano teaching hospital, Kano- Nigeria, Bayero journal of pure and appliedsciences, 2009; 2(2): 95-98
5. Wilson ML, Gaido L. Laboratory diagnosis of urinary tract infections in adult patients. Clin Infect Dis. 2004 Apr 15; 38 (8): 1150-8. Epub 2004 Apr 6.

6. Jennifer L. Young and David E. Soper. Urinalysis and urinary tract infection: update for clinicians. Infect Dis Obstet Gynecol 2001; 9(4):249-255.

7. Winkel $\mathrm{P}$, Statland BE, Jorgensen $\mathrm{K}$. Urine microscopy, an ill-defined method, examined by a multifactorial technique. Clin Chem. 1974 Apr;20 (4): 436-9.

8. Lorincz AE, Kelly DR, Dobbins GC, Cardone VS, Fuchs SA, Schilleci JL. Urinalysis: current status and prospects for the future. Ann Clin Lab Sci. 1999 JulSep; 29 (3):169-75.

9. Mittendorf R, Williams MA, Kass EH. Prevention of preterm delivery and low birth weight associated with asymptomatic bacteriuria. Clin Infect Dis. 1992 Apr;14 (4): $927-32$.

10. Colle JG, Miles RS, Watt B. Tests for identification of Bacteria. In Mackie and Mc Cartney's Practical Medical Microbiology. 14th ed.Edinburgh: Churchill Livingston;1996. p. 146.

11. Anushree, C. N, Chandrakanth, Manjunath, Veena. Relationship between pyuria and bacteruria in suspected urinary tract infection Medica Innovatica.2014; 3(2): p-84.

12. Kattel, H.P., S.K. Mishra, J.Acharya, A.S. Shah, B.P.Rijal and B.M.Pokharel. 2009. Relationship between pyuria and bacteriuria in suspected urinary tract infection. JNAMLS. 2009; 10 (1): 19-21.

13. Dongol A, Joshi DM, Gautam A. Detection of Pyuria versus Bacteriuria in Suspected Patients of Urinary Tract Infection. Nepal Journal of Science and Technology. 2014; 15(1): 129-132.

14. Ginsburg CM, McCracken GH Jr. Urinary tract infections in young infants. Pediatrics. 1982 Apr; 69 (4):409-12.

15. Maskell. Study of urinary tract infections children in one health distrct. BMJ;1994 pp: 309. 
Research Article

16. Samia S. Khamees. Urinary Tract Infection: Causative Agents, the Relation Between Bacteriuria and Pyuria. World Appl. Sci. J.2012; 20 (5): 683-686.

17. Dhakal, B.K., B.M. Pokhrel and J. Ahnn. Microscopic detection of urinary tract infection in Nepalese patients. J. Microbiol.2002; 40(4): 267-273.

18. Hooberman A,Choa HP,Keller DM et al.Prevalence of urinary tract infection in febrile infants. $j$ of pediatr. 1993;123(1):17-23.

19. Lam CN, Bremner AD, Maxwell JD, Murphy AV, Low WJ. Pyuria and bacteriuria. Arch Dis Child. 1967 Jun; 42(223):275-80.

20. Hooker JB, Mold JW, Kumar S. Sterile pyuria in patients admitted to the hospital with infections outside of the urinary tract. J Am Board Fam Med 2014;27(1): 97-103.

21. Macdermott RIJ. The interpretation of midstream urine microscopy and culture results in women who present acutely to the labour ward. BJOG 1994;10(1): 712-13.

22. Bachman JW, Heise RH, Naessens JM, Timmerman MG. A study of various tests to detect asymptomatic urinary tract infections in an obstetric population. JAMA. 1993 Oct 27;270(16):1971-4.

23. Wammanda RD, Aikhionbare HA, Ogala WN. Use of nitrite dipstick test in the screening for urinary tract infection in children. West Afr J Med. 2000 Jul-Sep; 19 (3) :206-8.

24. Shaw KN, McGowan KL, Gorelick MH, Schwartz JS. Screening for urinary tract infection in infants in the emergency department: which test is best? Pediatrics. 1998 Jun;101(6):E1.

25. Mangiarotti P, Pizzini C, Fanos V. Antibiotic prophylaxis in children with relapsing urinary tract infections: review. J Chemother.2000Apr;12(2):115-23.
26. Kristiansen BE. [Pathogenic bacteria in the urinary tract. Incidence and resistance behavior]. Tidsskr Nor Laegeforen. 1983 Aug 30;103(24):1684-6.

27. Prais D, Strussberg R. Bacterial susceptibility to oral antibiotics in community acquired urinary tract infection. Arch Dis Child 2003; 88(3): 215-8.

28. Ladhani S, Gransden W. Increasing antibiotic resistance among urinary tract isolates. Arch Dis Child. 2003 May;88(5):444-5.

29. Shaikh N, Shope TR, Hoberman A, Vigliotti A, Kurs-Lasky M, Martin JM. Association Between Uropathogen and Pyuria. Pediatrics. 2016 Jul;138(1). pii: e20160087. doi: 10.1542/peds.2016-0087. Epub 2016 Jun 21.

30. Huang CT, Leu HS, Ko WC. Pyuria and funguria. Lancet. 1995 Aug 26;346(8974):582-3.

31. Quintiliani R, Cunha B, Klimek J, Maderazo EG. Bacteremia after manipulation of the urinary tract: the importance of pre-existing urinary tract disease and compromised host defences. Postgrad Med J. 1978;54 (636): 668-671.

32. Wakabayashi G, Gelfland JA, Jung WK, Connolly RJ, Burke JF, Dinarello CA.Staphylococcus epidermidis induces complement activation, tumor necrosis factor and interleukin-1, a shock-like state and tissue injury in rabbits without endotoxemia: comparison to Escherichia coli. J Clin Invest. 1991;87 (6): 1925-1935.

33. Virtanen S, Oksanen T, Peltonen T. Colony counts and the diagnosis of urinary tract infection in infants and children. Counts from clean-voided urine specimens and from those collected in plastic bags. Ann Paediatr Fenn. 1962;8:269-77.

34. Houston IB. Pus Cell And Bacterial Counts in The Diagnosis Of Urinary Tract Infections in Childhood. Arch Dis Child. 1963 Dec;38:600-5.

\section{How to cite this article?}

M.J. Haja Abdul Nazeer, Y. Kavitha. Association between pyuria and uropathogen in suspected urinary tract infection. Trop J Path Micro 2017;3(2):223-228.doi: 10.17511/jopm.2017.i2.26. 